rpso

\title{
Danos Ocupacionais associados ao Crómio, com ênfase no setor da Conservação e Restauro de Obras de Arte
}

rpso.pt/danos-ocupacionais-associados-ao-cromio-com-enfase-no-setor-da-conservacao-e-restauro-de-obras-dearte/

January 11,2020

Santos M, Almeida A. Danos Ocupacionais associados ao Crómio, com ênfase no setor da Conservação e Restauro de Obras de Arte. Revista Portuguesa de Saúde Ocupacional on line. 2020, volume 9, 1-16DOI: 10. 31252/RPSO.11.01.2020

OCCUPATIONAL DAMAGE ASSOCIATED WITH CHROMIUM, ENFATISING ON CONSERVATORS-RESTORERS OF ART OBJECTS

Autores: Santos M(1), Almeida A(2)

\section{RESUMO}

\section{Introdução e Objetivo}

O setor da Conservação e Restauro ainda não foi abordado pela Saúde Ocupacional de uma forma completa ou exaustiva, pelo que se registam várias lacunas de conhecimento.

Os autores tiveram como objetivo recolher e resumir toda a informação que encontraram sobre o tema.

Os principais riscos associados ao Crómio distribuem-se por vários contextos médicos, ainda que com consensos diferentes, a nível de patologia cardiovascular, nefrológica, hepática, oncológica, dermatológica, otorrinolaringológica, pneumológica, oftalmológica e hematológica.

\section{Metodologia}

Foi realizada uma pesquisa em janeiro de 2019, considerando os motores de busca Scopus; PubMed/ MedLine; Web of Science; Science Direct; Academic Search Complete; CINALH; Database of Abstracts and Reviews; Central Register of Controlled Trials; Cochrane Database of Systematic Reviews; Nursing and Allied Health Collection; MedicLatina e RCAAP. 


\section{Conteúdo/ Resultados e Discussão}

Não se encontraram documentos que mencionassem detalhes relativos à toxicidade do Crómio neste setor.

Para outras áreas profissionais a informação foi escassa.

Os trabalhadores na indústria do vidro podem também estar expostos, bem como na metalurgia/ soldadura e indústria química.

\section{Limitaçõoes}

Os autores desenvolveram esforços no sentido de tentar que a sua pesquisa fosse exaustiva mas, uma vez concluída, perceberam que não encontraram dados relevantes sobre o doseamento do Crómio nos ambientes de trabalho da Conservação e Restauro, nem indicação de quais técnicas são possíveis utilizar e quais as preferenciais, tal como para a avaliação biológica do mesmo. Não foram encontrados artigos com descrição de medidas de proteção coletiva ou individual, sequer de forma genérica.

\section{Conclusões}

Desde longa data que são conhecidos malefícios concretos e sérios associados ao Crómio. Contudo, o setor da Conservação e Restauro é ainda muito pouco estudado em contexto de Saúde Ocupacional e os riscos do eventual contato com este agente não são exceção.

Seria muito pertinente que surgissem equipas motivadas para estudar este setor e colmatar parte das limitações encontradas, não desenvolvidas na literatura internacional.

PALAVRAS-CHAVE: conservação, restauro, conservador-restaurador, saúde ocupacional, medicina do trabalho, crómio.

\section{ABSTRACT}

\section{Introduction and Objective}

The Conservation and Restoration sector has not yet been fully or comprehensively addressed by Occupational Health, so there are several knowledge gaps.

The authors aimed to collect and summarize all the information they found on the topic.

The main risks associated with Chromium are spread across a variety of medical settings (albeit with different consensos) on cardiovascular, nephrological, hepatic, oncological, dermatological, otorhinolaryngological, pneumological, ophthalmic and haematological pathology.

\section{Methodology}

A survey was conducted in January 2019, considering Scopus search engines; PubMed / MedLine; Web of Science; Science Direct; Academic Search Complete; CINALH; Database of Abstracts and Reviews; Central Register of Controlled Trials; Cochrane Database of 
Systematic Reviews; Nursing and Allied Health Collection; MedicLatina and RCAAP.

\section{Content / Results and Discussion}

No documents were found mentioning details concerning Chromium toxicity in this sector.

For other professional areas information was scarce.

Workers in the glass industry may also be exposed as well as in metallurgy/ welding and the chemical industry.

\section{Limitations}

The authors made efforts to try to make their research exhaustive but, once completed, they realised that they did not find relevant data on Chromium dosing in Conservation and Restoration work environments, nor an indication of which techniques can be used and which are the preferred ones, including biological evaluation. No articles were found describing collective or individual protection measures, even in a generic way.

\section{Conclusions}

Concrete and serious harms associated with Chromium have long been known. However, the Conservation and Restoration sector is still very little studied in the context of Occupational Health and the risks of eventual contact with this agent are no exception.

It would be very pertinent to have motivated teams to study this sector and to address some of the limitations not developed in the international literature.

KEY WORDS: conservation, restoration, conservator-restorer, occupational health, occupational medicine, chromium.

\section{INTRODUÇÃO E OBJETIVO}

Os autores tiveram como objetivo recolher e resumir toda a informação que encontraram sobre o tema, sob o formato de uma Scoping Review, como ponto de partida para outros projetos que se afirmem como pertinentes, no contexto da saúde ocupacional destes profissionais.

Foi elaborada uma outra revisão, relativa aos riscos genéricos que o Crómio pode acarretar na saúde humana (e por isso relevantes para qualquer outro setor profissional onde este agente exista), para se abordar o tema de uma forma mais completa e se realizar uma introdução melhor fundamentada.

Segundo a bibliografia selecionada, os principais riscos associados ao Crómio distribuem-se por vários órgãos e sistemas, ainda que com consensos diferentes, a nível de: sistema cardiovascular; nefrotoxicidade; oncologia (seios perinasais, pulmão e estômago); 
dermatologia (eczema, úlcera); pneumologia (Bronquite Crónica e Enfizema); otorrinolaringologia (perfuração do septo nasal, laringite, epistaxes, ulceração da mucosa), endocrinologia (diabetes), oftalmologia e hematologia.

Foram consideradas consequências médicas pertinentes no contexto da obstetrícia e pediatria, uma vez que não é raro os ateliers estarem inseridos no domicílio dos Conservadores- Restauradores e, por vezes, sobretudo no passado, irem para lá crianças brincar (os autores encontraram relatos antigos nesse sentido). Para além disso, a perceção de risco concreto para os filhos pode ser muito mais motivadora para seguir as recomendações para um trabalho seguro e saudável, do que o seu próprio risco, para a generalidade dos trabalhadores.

\section{METODOLOGIA}

A pergunta de investigação considerada foi: O que está descrito na literatura relativamente aos riscos ocupacionais dos Conservadores/ Restauradores, associados à exposição ao Crómio?

Realizaram-se pesquisas informais prévias sobre o tema e percebeu-se que a literatura é muito escassa para este setor profissional; por isso, os autores optaram por não fazer restrições significativas associadas a ano de publicação, tipo de estudo, robustez metodológica, língua ou acesso imediato a texto completo.

Como critérios de inclusão consideraram-se:

- publicação entre 1980 e 2019

- idade igual ou superior a 18 anos

- exposição ao Crómio

Como critérios de exclusão foram assumidos:

estudos não pertinentes para o objetivo da revisão, ou seja, que não respondam à questão de investigação.

Foram considerados os seguintes motores de busca/ bases de dados: Scopus; PubMed/ MedLine; Web of Science; Science Direct; Academic Search Complete; CINALH; Database of Abstracts and Reviews; Central Register of Controlled Trials; Cochrane Database of Systematic Reviews; Nursing and Allied Health Collection; MedicLatina e RCAAP.

Foram também considerados documentos fornecidos por peritos da área e com pertinência para os objetivos estipulados, ou seja, com capacidade para responder à questão de investigação. Após análise da bibliografia dos documentos selecionados, houve a possibilidade de considerar os artigos aí mencionados, caso respondessem à pergunta de investigação. De igual forma, também se procuraram documentos publicados posteriormente, que tenham citado os inicialmente selecionados, de forma a avaliar se estes também poderiam dar algum contributo para elucidar os objetivos considerados. 
Nos primeiros oito quadros os autores sintetizaram as estratégias utilizadas para encontrar artigos pertinentes, nas diversas bases de dados/ motores de busca.

\section{CONTEÚDO}

\section{Caraterísticas do Crómio}

Trata-se de um oligoelemento, ou seja, um agente que participa em funções importantes no organismo, ainda que numa quantidade pequena; nomeadamente a nível do metabolismo dos hidratos de carbono, lípidos e proteínas [1].

Este agente apresenta vários estados de oxidação; a forma mais prevalente nos alimentos e no organismo é a trivalente (CrIII); este é razoavelmente estável e forma complexos com a água, ureia, amónia e ácidos orgânicos; geralmente só é tóxico com concentrações elevadas. Em circunstâncias alcalinas pode transformar-se em Crómio hexavalente (CrVI), que é muito perigoso, nomeadamente a nível de carcinogenicidade (por exemplo pulmonar) [1]. As versões mais comuns do crómio são a que ele está no estado oxidativo +3 (CRIII) e +6 (CRVI) [2].

Contudo, curiosamente, estão descritas consequências negativas associadas à carência de Crómio, nomeadamente a nível do metabolismo com os carbohidratos e lípidos [1].

\section{Principais Fontes de Crómio}

A água pode conter níveis elevados de Crómio (Cr) VI, devido ao uso como desinfetante e associado ao cloro [1]; já o Cr III que possa existir neste contexto, será proveniente da corrosão das condutas [1] [3].

A nível alimentar, englobando todas as formas de Crómio, considera-se que este pode ser encontrado em carnes processadas, cereais integrais, gema do ovo, café, nozes, vagem, brócolo, cerveja e vinho. As ostras podem atingir valores na ordem dos $12.6 \mu \mathrm{g} / \mathrm{g}$, os cogumelos 16.4, o vinho 7.6 e a maçã 7,5, por exemplo. Ainda assim, a ingestão de um adulto não costuma ser superior a 50- $200 \mu \mathrm{g}$ por dia [1].

A generalidade da população está então exposta ao crómio através dos alimentos e suplementos nutricionais, bem como água, ar e tabaco (neste último caso, sob o formato de CrVI) [2].

O Crómio (CrIII) é um metal essencial em quantidades vestigiais; a entrada do mesmo (esta versão do crómio em específico) para o organismo geralmente ocorre pela alimentação (sobretudo batata doce, milho, brócolo, maçã, uva, cereais integrais, aves domésticas/ peru, vaca e ostra) e ingestão de água contaminada [3].

Contudo, há indivíduos que consomem Crómio em suplementos e/ ou têm dispositivos médicos que libertam este agente (como próteses ortopédicas), podendo nestes casos atingir-se uma concentração sérica mais elevada [3]. 
A nível profissional, é utilizado também na produção de inox, pigmentos e na soldadura de aço inoxidável [1].

\section{Pontos de corte}

A NIOSH (National Institute for Occupational Safety and Health) elaborou normas para este agente, nomeadamente referindo que a concentração atmosférica de Cr VI não deverá ser superior a $1 \mu \mathrm{g} / \mathrm{m}^{3}$, para tempos de exposição não superiores a 10 horas diárias e 40 horas semanais; contudo, atualmente, em alguns contextos, considera-se $0,2 \mu \mathrm{g} / \mathrm{m}^{3}, 8$ horas por dia e 40 horas por semana [1].

\section{Vias de entrada}

O crómio tem como principal forma para entrar no organismo as vias inalatória, digestiva, cutânea e ocular [4].

\section{Comportamento dentro do organismo}

A absorção digestiva ocorre principalmente a nível do duodeno e íleo e na ordem dos 0.5 a $3 \%$; ainda assim, mais intensa no caso do Cr VI, versus Cr III. A absorção também parece ser inversa à quantidade ingerida [1].

Acredita-se que a reserva habitual de crómio no organismo humano não seja superior a 4.6 mg e localiza-se sobretudo no coração, fígado, pâncreas, pulmão, cérebro e baço [1].

O crómio pode competir com o ferro [1].

\section{Vias de excreção}

A maioria da excreção é realizada via urinária [1] [2]; ainda que também possa ocorrer através do suor e bílis [1]. Apresenta semivida no sangue de 13,9 dias. O crómio urinário e sérico pode refletir a exposição aguda [2].

\section{Tipos de Doseamentos disponíveis/ Diagnóstico de Intoxicação}

Nos artigos selecionados não se encontraram dados relativos a este item.

\section{Consequências Médicas atribuídas à exposição ao Crómio}

Um dos documentos selecionados mencionou que este agente apresentava evidência de danos a nível de doenças cardiovasculares [1]; contudo, outros autores discordam [2].

Pensa-se que o Crómio possa ser nefro e hepatotóxico [1] [4].

Acredita-se que também possa ser cancerígeno [4], nomeadamente a nível dos seios perinasais [5], pulmão [1] [6] e estômago [2].

Um dos artigos selecionados considerou que este agente pode-se associar a ulceração cutânea e dermatite de contato [1] [4] [7]. 
A nível otorrinolaringológico são mencionadas a perfuração do septo nasal [1] [4] [7] e Laringite [1]; Rinite, epistaxes e ulceração da mucosa [7].

Um dos documentos consultados realçou a relação existente com a Bronquite Crónica e o Enfizema pulmonar [1].

Hã quem defenda também a associação com a diabetes [1].

A nível oftalmológico é possível que ocorra irritação ocular [4].

Por sua vez, a nível hematológico poderão suceder leucocitose/ leucopenia, monocitose e/ ou eosinofilia [4].

\section{Tratamento}

Nenhum dos documentos selecionados mencionou dados relativos a técnicas de tratamento.

\section{CONTEÚDO OU RESULTADOS}

\section{Exposição ao Crómio em Conservadores/ Restauradores}

Este elemento foi descoberto por Vanquelin em 1797; o amarelo de crómio (cromato de chumbo) foi produzido a partir de 1803 e o óxido de crómio (verde) a partir de 1809; ainda que tóxicos, mas usados ainda hoje; os mais relevantes são (a nível de frequência de uso e toxicidade) o amarelo e o verde de crómio [4].

\section{Medidas de Proteção Coletiva e Individual}

Entre os documentos selecionados não se encontrou qualquer referência direta a eventuais medidas de proteção coletiva ou a EPIs (equipamentos de proteção individual), à exceção de luvas, num artigo (mas não especificando qualquer caraterística das mesmas) [7].

\section{Doenças Profissionais}

No quadro 9 estão transcritas as principais doenças profissionais associadas ao Crómio, em função do Decreto Regulamentar 76/2007, de 17 de julho.

\section{DISCUSSÃO}

Existindo tão pouca bibliografia relativa aos riscos médicos do Crómio em ConservadoresRestauradores, os autores optaram por inserir na secção de Discussão alguns dados relativos a outros profissionais que também possam contatar com este agente. Entre estes, os artistas que elaboram (ou sobretudo elaboraram no passado) obras de arte com pigmentos com Crómio, talvez sejam os mais adequados, ainda que também sobre estes a bibliografia seja muito reduzida.

Acredita-se que pintores famosos, em função dos pigmentos utilizados, estavam expostos a Crómio; nomeadamente Rubens, Renoir, Duffy (todos com o diagnóstico pioneiro na época de artrite reumatoide) e Klee (com semiologia que se poderá encaixar no que hoje se 
designa por esclerodermia). Supõe-se que a exposição a metais pesados possa ter contribuído para algumas patologias reumatológicas apresentadas [8].

Os artistas atuais estão muito menos expostos, até pelas diferentes condições de trabalho no atelier e cuidados na ingestão de alimentos e bebidas, que na altura não existiam [8].

Entre os hábitos nocivos dos artistas no passado destacam-se o não lavar adequadamente as mãos antes de comer ou de fumar e lamber os pinceis usados; para além disso, os pintores mais pobres por vezes comiam e dormiam no mesmo sítio que servia como atelier. Por vezes as roupas eram aquecidas para secarem melhor, evaporando-se quantidades razoáveis de agentes químicos ou até fazendo fogueiras no interior desse espaço multifunções, por vezes queimando objetos contaminados [8].

Os artistas de hoje usam pigmentos menos tóxicos, os produtos estão rotulados com avisos de perigo e já sabem que não é boa ideia lamber pinceis ou fazer fogueiras, sobretudo em espaço fechados. Os cigarros mais frequentemente são comprados que feitos e a comida e bebida estão isoladas dos produtos de trabalho, por vezes, dentro de frigoríficos e até noutra divisão separada [8].

A nível de dados laborais mais atuais, encontrou-se um artigo que mencionava que, no setor da inceneração poderá haver alguma exposição ao crómio [6]. Outro documento mencionou que, após realizar um workshop fotográfico com produtos que continham Crómio VI, surgiu num indivíduo prurido, eritema nos membros superiores e face, bem como edema digital e facial. A nível de equipamentos de proteção individual foram sugeridas luvas de borracha [7], no contexto atrás amencionado.

Os trabalhadores na indústria do vidro estão expostos a crómio. Genericamente este é utilizado na metalurgia e indústria química. Os soldadores de aço inoxidável estão expostos a CrVI via inalatória e este facilmente se reduz a CRIII no cólon e pulmão [2].

Tal como se mencionou atrás, a bibliografia selecionada não forneceu dados sobre Medidas de Proteção Coletiva. Em função da experiência clínica dos autores, poder-se-iam considerar:

- elaboração de protocolos onde se descreveria o procedimento e técnicas a utilizar para perceber se as peças apresentavam ou não Crómio

- potenciação da ventilação das salas com objetos contaminados com Crómio e especificação das características mínimas da mesma

- rotação das tarefas mais perigosas entre os diversos Conservadores/ Restauradores da mesma empresa, se possível

- organização do trabalho de forma a alternar projetos com exposição ao Crómio com outras tarefas sem exposição ao Crómio, se concretizável

- formação sobre os riscos médicos do Crómio e procedimentos laborais associados

- vigilância adequada pelo Médico do Trabalho com exames periódicos (e ocasionais, se necessário)

- acesso a doseamentos biológicos associados ao Crómio, orientados pelo Médico do Trabalho (indicando quais os tipos de amostras possíveis e quais as preferencialmente utilizadas) 
- acesso a doseamentos nas superfícies e/ ou atmosfera do ambiente de trabalho, orientados pelo Técnico de Segurança (especificando quais técnicas poderiam ser utilizadas e quais as mais pertinentes)

- listagem e acesso a EPIs adequados (em modelo e material), selecionados pelo Técnico de Segurança

- organização de serviço de lavandaria, para que as fardas/batas/ aventais e/ ou manguitos dos funcionários sejam adequadamente lavados, sem contaminar outras peças de roupa ou locais, no domicílio de cada Conservador- Restaurador.

Quanto a EPIs, a bibliografia selecionada apenas mencionou o uso de luvas; em função da experiência clínica dos autores, poder-se-iam também considerar macacão, farda, bata ou avental; manguitos; máscara e/ ou viseira; óculos e protetores de calçado (em contexto químico) ou calçado exclusivo para o local de trabalho.

\section{LIMITAÇÕES}

Os autores desenvolveram esforços no sentido de tentar que a sua pesquisa fosse exaustiva mas, uma vez concluída, perceberam que não encontraram dados relevantes sobre:

- doseamento do Crómio nos ambientes de trabalho da Conservação e Restauro em geral e muito menos nos diversos subsetores e incluindo tarefas teoricamente mais problemáticas e menos problemáticas (para balizar); nem indicação de quais técnicas são possíveis utilizar e quais as preferenciais

- doseamento biológico do Crómio numa amostra geral de profissionais do setor, expostos a este agente, muito menos nos subsetores atrás mencionados ou por tipo de amostra biológica; nem referências ao tipo de amostra mais adequado a cada situação

- avaliação do risco associado para os Conservadores- Restauradores, em função dos doseamentos obtidos e restante análise ao posto de trabalho

- descrição de medidas de proteção coletiva

- descrição de EPI adequados (sequer de forma genérica, quanto mais especificando modelos e/ ou materiais).

\section{CONCLUSÕES}

Desde longa data que são conhecidos malefícios concretos e sérios associados ao Crómio. Contudo, o setor da Conservação e Restauro é ainda muito pouco estudado em contexto de Saúde Ocupacional e os riscos do eventual contato com este elemento não são exceção.

Seria muito pertinente que surgissem equipas motivadas para estudar este setor e colmatar parte das limitações encontradas, não desenvolvidas na literatura internacional.

\section{AGRADECIMENTOS}

Não se aplicam. 


\section{CONFLITO DE INTERESSES}

Não se aplicam.

\section{FINANCIAMENTO}

Não se aplica.

\section{BIBLIOGRAFIA}

[1] Barros C. Crómio, Fisiologia e Fisiopatologia. Tese de Mestrado em Ciências Farmacêuticas. Instituto Superior de Ciências da Saúde Egas Moniz. 2014, 1-63.

[2] Wingren G, Axelson O. Epidemiologic studies of occupational cancer as related to complex mixtures of trace elements in the art glass industry. Scandinavian Journal of Work and Environmental Health. 1993, 19(1), 95-100.

[3] Monnot A, Christian W, Paustenbach D, Finley B. Correlation of blood Cr (III) and adverse health effects: application of PBPK modeling to determine non-toxic blood concentrations. Critical Reviews in Toxicology. 2014, 44(7), 618-637. DOI: 10.3109/10408444.2014.92647.

[4] Cruz A. O risco da arte. A toxicidade dos materiais utilizados na execução e conservação de pinturas de cavalete. A Conservação e o Restauro do Património", Associação Profissional de Conservadores- Restauradores de Portugal.

[5] Binazzi A, Ferrante P, Marinaccio A. Occupational exposure and sinonasal cancer: a systematic review and meta-analysis". BMC Cancer. 2015, 15(49), 1-18. DOI: $10.1196 / \mathrm{s} 12885-015-1042-2$

[6] Mauriella M, Sbordone C, Montuori P, Alfano R, Triassi M, lavicol I et al. Biomonitoring of toxic metals in incinerator workers: a systematic review. Toxicology Letters. 2017, 272, 8-28. DOI: 10.1016/J.toxlet.2017.02.021

[7] Sem autor. Epidemiologic notes and reports- Chromium sensitization in a Artist workshop. 1982, CDC, 31(9), 111-112.

[8] Pedersen L, Permin H. Rheumatic Disease, Heavy-metal pigments and the Great Masters". The Lancet, 1988 1267-1269. 
Quadro 1: Resumo dos dados mais relevantes associados à pesquisa no motor de busca EBSCO (CINALH, Medline, Database of Abstracts and Reviews, Central Register of Controlled Trials, Cochrane Database of Systematic Reviews, Nursing \& Allied Health Collection e MedicLatina)

\begin{tabular}{|c|c|c|c|c|c|c|}
\hline Data & $\begin{array}{l}\text { Pass- } \\
\text { word } 1\end{array}$ & $\begin{array}{l}\text { Pass-word } 2 \\
\text { e seguintes, } \\
\text { caso } \\
\text { existam }\end{array}$ & Critérios & $\begin{array}{l}\mathrm{N}^{\circ} \text { de } \\
\text { documentos } \\
\text { obtidos }\end{array}$ & $\begin{array}{l}\mathrm{N}^{\circ} \mathrm{da} \\
\text { pesquisa }\end{array}$ & $\begin{array}{l}\text { Pesquisa } \\
\text { efetuada } \\
\text { ou não }\end{array}$ \\
\hline \multirow[t]{8}{*}{$2019 / 01 / 11$} & & & & 629 & 1 & não \\
\hline & 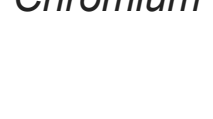 & $\begin{array}{l}\text { Systematic } \\
\text { Review }\end{array}$ & $\begin{array}{l}\text { desde } \\
2014\end{array}$ & 12 & 2 & $\operatorname{sim}$ \\
\hline & & Conservation & \multirow{6}{*}{$\begin{array}{l}\text { humano+ } \\
\text { resumo } \\
\text { disponível }\end{array}$} & 41 & 3 & $\operatorname{sim}$ \\
\hline & & Restoration & & 525 & 4 & não \\
\hline & & Conservator & & 0 & 5 & não \\
\hline & & Restorer & & 0 & 6 & não \\
\hline & & $\begin{array}{l}\text { Cultural } \\
\text { heritage }\end{array}$ & & 0 & 7 & não \\
\hline & & Art & & 33 & 8 & $\operatorname{sim}$ \\
\hline
\end{tabular}

Quadro 2: Resumo dos dados mais relevantes associados à pesquisa no motor de busca RCAAP

\begin{tabular}{llllll} 
Data & $\begin{array}{l}\text { Pass- } \\
\text { word 1 }\end{array}$ & Critérios & $\begin{array}{l}\mathbf{N}^{\circ} \text { de } \\
\text { documentos } \\
\text { obtidos }\end{array}$ & $\begin{array}{l}\mathbf{N}^{\circ} \text { da } \\
\text { pesquisa }\end{array}$ & $\begin{array}{l}\text { Pesquisa } \\
\text { efetuada ou } \\
\text { não }\end{array}$ \\
\hline $2019 / 01 / 11$ & Crómio & $\begin{array}{l}\text { Pesquisa } \\
\text { avançada } \\
\text { título }\end{array}$ & 53 & 9 & sim
\end{tabular}

Quadro 3: Resumo dos dados mais relevantes associados à pesquisa no motor de busca PubMed/ MedLine

\begin{tabular}{|c|c|c|c|c|c|c|}
\hline Data & $\begin{array}{l}\text { Pass- } \\
\text { word } 1\end{array}$ & $\begin{array}{l}\text { Pass-word } 2 \\
\text { e seguintes, } \\
\text { caso } \\
\text { existam }\end{array}$ & Critérios & $\begin{array}{l}N^{\circ} \text { de } \\
\text { documentos } \\
\text { obtidos }\end{array}$ & $\begin{array}{l}N^{0} \text { da } \\
\text { pesquisa }\end{array}$ & $\begin{array}{l}\text { Pesquisa } \\
\text { efetuada } \\
\text { ou não }\end{array}$ \\
\hline \multirow[t]{3}{*}{$2019 / 01 / 20$} & \multirow{3}{*}{ Chromium } & & & 36.936 & 10 & não \\
\hline & & $\begin{array}{l}\text { Systematic } \\
\text { Review }\end{array}$ & $\begin{array}{l}\text { desde } \\
2014\end{array}$ & 43 & 11 & $\operatorname{sim}$ \\
\hline & & Conservation & humano+ & 194 & 12 & não \\
\hline
\end{tabular}




\begin{tabular}{|c|c|c|c|c|}
\hline $\begin{array}{l}\text { And } \\
\text { Restoration }\end{array}$ & disponivel & 8 & 13 & $\operatorname{sim}$ \\
\hline Conservator & & 0 & 14 & não \\
\hline Restorer & & 240 & 15 & não \\
\hline $\begin{array}{l}\text { Cultural } \\
\text { heritage }\end{array}$ & & 1 & 16 & $\operatorname{sim}$ \\
\hline Art & & 79 & 17 & sim \\
\hline
\end{tabular}

Quadro 4: Resumo dos dados mais relevantes associados à pesquisa no motor de busca Science Direct

\begin{tabular}{|c|c|c|c|c|c|c|}
\hline Data & $\begin{array}{l}\text { Pass- } \\
\text { word } 1\end{array}$ & $\begin{array}{l}\text { Pass-word } 2 \\
\text { e seguintes, } \\
\text { caso } \\
\text { existam }\end{array}$ & Critérios & $\begin{array}{l}\mathrm{N}^{\circ} \text { de } \\
\text { documentos } \\
\text { obtidos }\end{array}$ & $\begin{array}{l}N^{0} \text { da } \\
\text { pesquisa }\end{array}$ & $\begin{array}{l}\text { Pesquisa } \\
\text { efetuada } \\
\text { ou não }\end{array}$ \\
\hline \multirow[t]{9}{*}{$2019 / 01 / 20$} & \multirow{8}{*}{ Chromium } & & & 193.812 & 18 & não \\
\hline & & $\begin{array}{l}\text { Systematic } \\
\text { Review }\end{array}$ & $\begin{array}{l}\text { desde } \\
2014\end{array}$ & 3.380 & 19 & não \\
\hline & & & $\begin{array}{l}\text { Review } \\
\text { articles }\end{array}$ & 935 & 20 & não \\
\hline & & Conservation & \multirow{6}{*}{$\begin{array}{l}\text { humano+ } \\
\text { resumo } \\
\text { disponível }\end{array}$} & 664 & 21 & não \\
\hline & & $\begin{array}{l}\text { And } \\
\text { Restoration }\end{array}$ & & 85 & 22 & $\operatorname{sim}$ \\
\hline & & Conservator & & 6 & 23 & $\operatorname{sim}$ \\
\hline & & Restorer & & 4 & 24 & $\operatorname{sim}$ \\
\hline & & $\begin{array}{l}\text { Cultural } \\
\text { heritage }\end{array}$ & & 42 & 25 & $\operatorname{sim}$ \\
\hline & & Art & & 1066 & 26 & não \\
\hline
\end{tabular}

Quadro 5: Resumo dos dados mais relevantes associados à pesquisa no motor de busca Scopus

\begin{tabular}{lllllll} 
Data & $\begin{array}{l}\text { Pass- } \\
\text { word 1 }\end{array}$ & $\begin{array}{l}\text { Pass-word 2 } \\
\text { e seguintes, } \\
\text { caso } \\
\text { existam }\end{array}$ & Critérios & $\begin{array}{l}\mathbf{N}^{\circ} \text { de } \\
\text { documentos } \\
\text { obtidos }\end{array}$ & $\begin{array}{l}\mathbf{N}^{\circ} \text { da } \\
\text { pesquisa }\end{array}$ & $\begin{array}{l}\text { Pesquisa } \\
\text { efetuada } \\
\text { ou não }\end{array}$ \\
\hline $2019 / 01 / 20$ & Chromium & & 200.097 & 27 & não \\
\cline { 3 - 7 } & & $\begin{array}{l}\text { Systematic } \\
\text { Review }\end{array}$ & $\begin{array}{l}\text { desde } \\
2014\end{array}$ & 36 & 28 & sim \\
& & & &
\end{tabular}




\begin{tabular}{|c|c|c|c|c|}
\hline Conservation & \multirow{6}{*}{$\begin{array}{l}\text { humano+ } \\
\text { resumo } \\
\text { disponível }\end{array}$} & 888 & 29 & não \\
\hline $\begin{array}{l}\text { And } \\
\text { Restoration }\end{array}$ & & 47 & 30 & $\operatorname{sim}$ \\
\hline Conservator & & 7 & 31 & $\operatorname{sim}$ \\
\hline Restorer & & 1 & 32 & $\operatorname{sim}$ \\
\hline $\begin{array}{l}\text { Cultural } \\
\text { heritage }\end{array}$ & & 15 & 33 & $\operatorname{sim}$ \\
\hline Art & & 531 & 34 & não \\
\hline $\begin{array}{l}\text { Art } \\
\text { (medicine) }\end{array}$ & & 65 & 35 & $\operatorname{sim}$ \\
\hline
\end{tabular}

Quadro 6: Resumo dos dados mais relevantes associados ao motor de busca Academic Search Complete

\begin{tabular}{|c|c|c|c|c|c|c|}
\hline Data & $\begin{array}{l}\text { Pass- } \\
\text { word } 1\end{array}$ & $\begin{array}{l}\text { Pass-word } 2 \\
\text { e seguintes, } \\
\text { caso } \\
\text { existam }\end{array}$ & Critérios & $\begin{array}{l}\mathrm{N}^{\circ} \text { de } \\
\text { documentos } \\
\text { obtidos }\end{array}$ & $\begin{array}{l}\mathrm{N}^{\circ} \text { da } \\
\text { pesquisa }\end{array}$ & $\begin{array}{l}\text { Pesquisa } \\
\text { efetuada } \\
\text { ou não }\end{array}$ \\
\hline \multirow[t]{8}{*}{$2019 / 01 / 26$} & & & & 39.520 & 36 & não \\
\hline & & $\begin{array}{l}\text { Systematic } \\
\text { Review }\end{array}$ & $\begin{array}{l}\text { desde } \\
2014\end{array}$ & 35 & 37 & $\operatorname{sim}$ \\
\hline & & Conservation & \multirow{6}{*}{$\begin{array}{l}\text { humano+ } \\
\text { resumo } \\
\text { disponível }\end{array}$} & 222 & 38 & não \\
\hline & & $\begin{array}{l}\text { And } \\
\text { Restoration }\end{array}$ & & 14 & 38 & $\operatorname{sim}$ \\
\hline & & Conservator & & 1 & 40 & $\operatorname{sim}$ \\
\hline & & Restorer & & 0 & 41 & não \\
\hline & & $\begin{array}{l}\text { Cultural } \\
\text { heritage }\end{array}$ & & 9 & 42 & $\operatorname{sim}$ \\
\hline & & Art & & 475 & 43 & não \\
\hline
\end{tabular}

Quadro 7: Resumo dos dados mais relevantes associados à pesquisa no motor de busca Web of Science

\begin{tabular}{lllllll} 
Data & $\begin{array}{l}\text { Pass- } \\
\text { word 1 }\end{array}$ & $\begin{array}{l}\text { Pass-word 2 } \\
\text { e seguintes, } \\
\text { caso } \\
\text { existam }\end{array}$ & Critérios & $\begin{array}{l}\mathbf{N}^{\circ} \text { de } \\
\text { documentos } \\
\text { obtidos }\end{array}$ & $\begin{array}{l}\mathbf{N}^{\circ} \text { da } \\
\text { pesquisa }\end{array}$ & $\begin{array}{l}\text { Pesquisa } \\
\text { efetuada } \\
\text { ou não }\end{array}$ \\
\hline $2019 / 01 / 27$ & Chromium & 105.217 & 44 & não \\
\cline { 5 - 6 } & & &
\end{tabular}




\begin{tabular}{|c|c|c|c|c|}
\hline $\begin{array}{l}\text { Systematic } \\
\text { Review }\end{array}$ & $\begin{array}{l}\text { desde } \\
2014\end{array}$ & 52 & 45 & $\operatorname{sim}$ \\
\hline Conservation & \multirow{6}{*}{$\begin{array}{l}\text { humano+ } \\
\text { resumo } \\
\text { disponível }\end{array}$} & 159 & 46 & não \\
\hline $\begin{array}{l}\text { And } \\
\text { Restoration }\end{array}$ & & 6 & 47 & $\operatorname{sim}$ \\
\hline Conservator & & 3 & 48 & $\operatorname{sim}$ \\
\hline Restorer & & 0 & 49 & não \\
\hline $\begin{array}{l}\text { Cultural } \\
\text { heritage }\end{array}$ & & 12 & 50 & sim \\
\hline Art & & 298 & 51 & não \\
\hline $\begin{array}{l}\text { Art } \\
\text { (medicine) }\end{array}$ & & 11 & 52 & $\operatorname{sim}$ \\
\hline
\end{tabular}

Quadro 8: Artigos selecionados de cada pesquisa

\begin{tabular}{|c|c|c|c|c|c|}
\hline $\begin{array}{l}\mathrm{N}^{\circ} \text { das } \\
\text { pesquisas } \\
\text { efetivadas } \\
\text { em que se } \\
\text { selecionou } \\
\text { pelo menos } \\
\text { um artigo }\end{array}$ & $\begin{array}{l}\mathrm{N}^{\circ} \text { de artigos } \\
\text { selecionados } \\
\text { após a } \\
\text { leitura do } \\
\text { título }\end{array}$ & $\begin{array}{l}\mathrm{N}^{0} \text { de artigos } \\
\text { selecionados } \\
\text { após a } \\
\text { leitura do } \\
\text { resumo }\end{array}$ & $\begin{array}{l}\text { Justificação } \\
\text { de } \\
\text { exclusão }\end{array}$ & $\begin{array}{l}\text { Inclusão e } \\
\text { codificação } \\
\text { inicial }\end{array}$ & Títulos \\
\hline 2 & 8 & & & 2.1 & $\begin{array}{l}\text { "Occupational } \\
\text { exposure and } \\
\text { sinonasal } \\
\text { cancer: a } \\
\text { systematic } \\
\text { review and } \\
\text { meta-analysis" }\end{array}$ \\
\hline 8 & 30,33 & & & $8.1,8.2$ & $\begin{array}{l}\text { "Epidemiologic } \\
\text { notes and } \\
\text { reports- } \\
\text { Chromium } \\
\text { sensitization in } \\
\text { a Artist } \\
\text { workshop" } \\
\text { "Epidemiologic } \\
\text { studies of } \\
\text { occupational } \\
\text { cancer as } \\
\text { related to } \\
\text { complex } \\
\text { mistures of } \\
\text { trace elements } \\
\text { in the art glass } \\
\text { industry" }\end{array}$ \\
\hline
\end{tabular}




\begin{tabular}{|c|c|c|c|c|}
\hline 9 & 1 & & 9.1 & $\begin{array}{l}\text { "Crómio, } \\
\text { Fisiologia e } \\
\text { Fisiopatologia. } \\
\text { Tese de } \\
\text { Mestrado em } \\
\text { Ciências } \\
\text { Farmacêuticas" }\end{array}$ \\
\hline 11 & 35 & $\begin{array}{l}\text { Repetido } \\
2.1\end{array}$ & & \\
\hline 17 & 69,73 & $\begin{array}{l}\text { Repetido } \\
8.1\end{array}$ & 17.1 & $\begin{array}{l}\text { "Rheumatic } \\
\text { Disease, } \\
\text { Heavy-metal } \\
\text { pigments and } \\
\text { the Great } \\
\text { Masters" }\end{array}$ \\
\hline 30 & 7,30 & $\begin{array}{l}\text { Não } \\
\text { pertinente }\end{array}$ & & $\begin{array}{l}\text { "Correlation of } \\
\text { blood Cr (III) } \\
\text { and adverse } \\
\text { health effects: } \\
\text { application of } \\
\text { PBPK } \\
\text { modeling to } \\
\text { determine non- } \\
\text { toxic blood } \\
\text { concentrations" }\end{array}$ \\
\hline 35 & 57 & $\begin{array}{l}\text { Repetido } \\
17.1\end{array}$ & & \\
\hline 38 & 13,21 & $\begin{array}{l}\text { Repetidos } \\
2.1 \text { e } 38.1\end{array}$ & & $\begin{array}{l}\text { "Biomonitoring } \\
\text { of toxic metals } \\
\text { in incineration } \\
\text { workers: a } \\
\text { systematic } \\
\text { review" }\end{array}$ \\
\hline
\end{tabular}

Quadro 9: Lista das doenças profissionais possíveis neste setor.

\begin{tabular}{llll} 
Código & Fatores de risco & Formas clínicas/ Risco & Prazo \\
\hline 31.03 & Crómio e seus compostos & Ulcerações do septo nasal/ cutâneas & 30 dias \\
& & Dermatite alérgica & 15 dias \\
& Dermatite irritativa & 7 dias \\
& Rinite & 15 dias \\
& Asma & 15 dias \\
& Cancro pulmonar & 30 anos \\
& Cancro cavidades perinasais & 30 anos
\end{tabular}




\section{(1)Mónica Santos}

Licenciada em Medicina; Especialista em Medicina Geral e Familiar; Mestre em Ciências do Desporto; Especialista em Medicina do Trabalho e Doutoranda em Segurança e Saúde Ocupacionais, na Faculdade de Engenharia da Universidade do Porto. Presentemente a exercer nas empresas Medicisforma, Servinecra, Securilabor, Medimarco e Tradsafety; Diretora Clínica da empresa Quercia; Diretora da Revista Portuguesa de Saúde Ocupacional on line. Endereços para correspondência: Rua Agostinho Fernando Oliveira Guedes, 42, 4420-009 Gondomar. E-mail: s_monica_santos@hotmail.com

\section{(2)Armando Almeida}

Enfermeiro Especialista em Enfermagem Comunitária, com Competência Acrescida em Enfermagem do Trabalho. Doutorado em Enfermagem; Mestre em Enfermagem Avançada; Pós-graduado em Supervisão Clínica e em Sistemas de Informação em Enfermagem; Professor Auxiliar Convidado na Universidade Católica Portuguesa, Instituto da Ciências da Saúde - Escola de Enfermagem (Porto) onde Coordena a Pós-Graduação em Enfermagem do Trabalho; Diretor Adjunto da Revista Portuguesa de Saúde Ocupacional on line.4420-009 Gondomar. E-mail: aalmeida@porto.ucp.pt 